\title{
Apparent mineralocorticoid excess
}

INSERM

\section{Source}

INSERM. (1999). Orphanet: an online rare disease and orphan drug data base. Apparent mineralocorticoid excess. ORPHA:320

Apparent mineralocorticoid excess (AME) is a rare form of pseudohyperaldosteronism characterized by very early-onset and severe hypertension, associated with low renin levels and hypoaldosteronism. 